\title{
Serological and Molecular Characterization Detects Unique Rice Yellow Mottle Virus Strains in Kenya
}

\author{
Anthony Simiyu Mabele ${ }^{1, *}$, Benard Mukoye², Denis Misiko Mukhongo ${ }^{3}$ \\ ${ }^{1}$ Department of Agriculture and Land Use Management (ALUM), School of Agriculture, Veterinary Science and Technology (SAVET), \\ Masinde Muliro University of Science and Technology (MMUST), Kakamega, Kenya \\ ${ }^{2}$ Department of Phytosanitary and Biosafety, Kenya Plant Health Inspectorate Service (KEPHIS), Nairobi, Kenya \\ ${ }^{3}$ Department of Biological and Environmental Sciences, Faculty of Science, Kibabii University (KIBU), Bungoma, Kenya
}

Email address:

mabeleanthony@gmail.com (A. S. Mabele)

${ }^{*}$ Corresponding author

\section{To cite this article:}

Anthony Simiyu Mabele, Benard Mukoye, Denis Misiko Mukhongo. Serological and Molecular Characterization Detects Unique Rice Yellow Mottle Virus Strains in Kenya. American Journal of Plant Biology. Vol. 5, No. 4, 2020, pp. 120-124.

doi: 10.11648/j.ajpb.20200504.17

Received: November 10, 2020; Accepted: November 23, 2020; Published: November 30, 2020

\begin{abstract}
Rice (Oryza sativa L.) is an economically important food crop in western Kenya but its production remains very low due to abiotic and biotic constraints. Rice yellow mottle disease (RYMD) caused by Rice yellow mottle virus (RYMV, genus: Sobemovirus) can cause up to $100 \%$ yield loss. This study characterized and determined the genetic diversity of RYMV strains in the ten isolates collected in February 2020 from both symptomatic and asymptomatic plants in western Kenya. The samples from the two rice fields A and B had two major common rice varieties of IR; field A (IR 2793) and field B (IR 2793-81). Total RNA was extracted using GeneJET Plant RNA Purification Mini Kit followed by RT-PCR using RYMV CP specific primers. The PCR products were sequenced by Sanger sequencing technology. Phylogenetic analysis was done by MEGA X. RYMV presence was confirmed serologically by DAS-ELISA. Isolates Ke_A1, KeB3 and KeB4 are novel sequences. KeB3 and $\mathrm{KeB} 4$ isolates clustered uniquely from the other Kenyan sequences depicting new evolutionary diversity. KeB3 and KeB4 shared 99\% sequence identity with Ke105 and Ke101, while isolate Ke_A1 shared 98\% identity with Ke101 and 99\% with Ke105. Phylogenetic analysis of the CP gene sequences revealed that the isolates from Uganda (Ug), Kenya (Ke) and Tanzania (Tz) clustered together by country, implying that there was a possibility of single introduction of the RYMV CP gene in the three East African (EA) countries once, before further local viral diversity occurred in each country with new recombinations for further research.
\end{abstract}

Keywords: Genetic Diversity, Novel Sequences, Rice yellow mottle virus, Western Kenya

\section{Introduction}

Rice (Oryza sativa L.) is the most important staple food crop worldwide. The rice grain is rich in dietary starch and protein, although it does not contain all the essential amino acids. Rice is a monocot plant of the order Oryzeae, family Poaceae, and genus Oryza. Cultivated rice belongs to two species, Oryza sativa (Asian rice) and Oryza glaberrima (African rice). In Kenya, rice is the third staple food crop after maize and wheat. It is grown by small scale farmers as a cash crop and food crop under government owned schemes like Mwea Tebere, Bunyala and Ahero irrigation schemes [1].
Rice cultivated on schemes accounts for about $95 \%$ of total domestic production. The remaining $5 \%$ is grown under rainfed conditions in coastal Kenya areas of Kilifi, Kwale, Tana River and in some parts of western Kenya like Bungoma, Busia and Kakamega. Rice (Oryza sativa L.) cultivation in western Kenya is one of the food baskets of the country for about $1 / 3$ of the country's population. About $80 \%$ of the rice grown in Kenya is from irrigation schemes established by government while the remaining $20 \%$ is produced under rainfed conditions. Rice consumption in Kenya has gone up $(300,000$ ton/year) while production rates are not commensurate and stands at 110,000 ton/year, catering for only $32 \%$ of the rice demand in Kenya [2]. Inability of Kenya 
to reach self-sufficiency in rice production is as a result of rice industry facing several constraints, amongst them Rice Yellow Mottle Disease (RYMD). In western Kenya, a survey done in 2012 reported RYMD incidences ranging between 1$40 \%$ and can lead to yield loss of up to $100 \%$ [2]. There is urgent need to address RYMD genomic diversity and distribution to facilitate breeding for resistant cultivars, and eliminate the trend of over-reliance on imports to meet the ever increasing demand for rice. There is limited information on Rice yellow mottle virus (RYMV) strains in western Kenya causing high RYMD incidence and severity. Molecular characterization of RYMV in isolates of western Kenya, will help unravel the unknown strains that will help understand the extent of recombination in RYMV genomic diversity and evolutionary biology for pathological plant breeding.

The RYMV occurrence is restricted only to Africa [3] and its offshore islands of Madagascar [4]. The survey done in neighbouring Uganda in September 2009 to determine the incidence and severity of RYMD, established that RYMD incidence and severity were high with mean values of $72 \%$ and 2.3 respectively. The S4 strain of RYMV was the most prevalent with narrow serological and biological variability [5]. In Tanzania, the survey done indicated RYMD incidence of $70 \%$ which positively correlated with the vectors (Chaetocnema sp. and Oxya hyla) suggesting that these vectors are responsible for the new spread of RYMV [6]. Similar additional surveys and molecular analysis revealed a co-existence within the same field of S4, S5 and S6 strains of RYMV in Eastern African region [6]. In Kenya, a survey done in 2012 in western Kenya, reported RYMD incidences ranging from $1-40 \%[7,8]$. This study unravels RYMV novel genetic diversity as a strong signal to identify the evolutionary mutation rate of the virus and be statistically tested in order to avoid spurious results. This will help in changing rice cultivation in the mainland Africa through molecular genetic breeding for resistance/tolerance. There are six distinct variant strains of RYMV that causes the disease [9], namely; S1, S2 and S3 found in West and Central Africa while S4, S5 and S6 are majorly found in East Africa [10]. The genetic diversity of RYMV in western Kenya isolates is inadequately documented because RYMV is a singlestranded positive-sense RNA species (genus: Sobemovirus; family: Solemoviridae) with a ca. 4,450-nucleotide-long genome organized into five open reading frames (ORFs) [11]. ORF1 is located at the 5' end of the genome, it encodes a small protein (P1) involved in virus movement and in gene silencing suppression. The ORF2 encodes the central polyprotein that has two overlapping ORFs. ORF2a encodes a serine protease and a viral genome-linked protein that determines the virulence. ORF2b is translated through a ribosomal frame shift mechanism as a fusion protein which encodes an RNA-dependent-RNA-polymerase (RdRp) gene. ORF4 is translated from a sub-genomic RNA at the 3' end of the genome and encodes the coat protein $(\mathrm{CP})$ gene. Research by [12] reported the presence of a fifth ORF (ORFx) conserved in all Sobemoviruses which overlaps the 5' end of the ORF2a in the $\mathrm{p} 2$ reading frame. According to [13], there is no sufficient evidence of intra-ORF4 recombination with the exception of a localized strain recently found in western Kenya. The sequence diversity data from this research will help unravel the evolutionary divergence of RYMV RNA genomic strains, helpful in Pathogen-Derived Resistance (PDR) breeding through recombinant DNA technologies and germplasm biofortification.

\section{Materials and Methods}

\subsection{Sample Collection}

This study focused on visual symptoms of RYMV in western Kenya. The disease diagnostic survey to determine RYMD occurrence was conducted in two rice fields (A and B) within the Ahero rice irrigation scheme representing the Lower Midland 3 (LM 3) Agro-Ecological Zone (AEZ) in Kisumu County, managed by the government through National Irrigation Board (NIB). The samples from the two rice fields $\mathrm{A}$ and $\mathrm{B}$ had two major common rice varieties of IR susceptible to RYMV, field A (IR 2793 variety) and field B (IR 2793-8-1 variety). The popular IR rice variety that is susceptible to RYMV was collected from field A (IR 2793 rice type) and from field $B$ (IR 2793-8-1 rice type). The leafy symptomatic and asymptomatic samples were collected in February 2020 from the farmers' fields in a cool box and taken to the laboratory for serological and molecular diagnostics.

\subsection{Serological Detection}

Serological diagnostics was done using the Double Antibody-Sandwich Enzyme-Linked Immunosorbent Assay (DAS-ELISA) protocol according to [14]. Concentration of the virus in the infected leaf was approximated with reference to standardized optical density (OD) of a positive isolate from the Institut de Recherche pour le Développement (IRD) screenhouse. The antibody used was nondiscriminatory and worked for all the isolates. An ELISA microplate reader was used to detect the OD values at 405 $\mathrm{nm}$ after 2 hours. The isolates that were considered positive were those with $\mathrm{OD}$ values of more than twice the value of the negative control [15].

\subsection{Molecular Diagnostics}

A total of seven isolates from the ELISA samples (Plate 1) were selected to investigate the diversity of RYMV strains. Total RNA was extracted using the GeneJET Plant Purification Mini Kit (Thermo Scientific) according to the manufacturer's protocol. The leaf tissue was homogenized in liquid nitrogen and in lysis buffer provided in the kit. The RYMV F III 5'-CAAAGATGGCCAGGAA-3' and RYMV R M5'-CgCTCAACATCCTTTTCAgggTAg-3' primers at 10 $\mu \mathrm{M}$ were used in transcription and amplification of the targeted Coat Protein (CP) gene [14]. The sense primers were also utilized in the Reverse Transcriptase-Polymerase Chain 
Reaction (RT-PCR) to transcribe and amplify genome fragments within the coat protein (CP) gene (nt 3447 to 4166 ) [14]. Amplification of the two-step RT-PCR products was done using the 2 RYMV specific primers (primer 3' II M 5' III) under the following conditions; Denaturation at $94^{\circ} \mathrm{C}$ for 5 minutes followed by 30 cycles at $94^{\circ} \mathrm{C}$ for 1 minute, Hybridization at $55^{\circ} \mathrm{C}$ for 30 seconds, Elongation at $72^{\circ} \mathrm{C}$ for 1 minute and final extension at $72^{\circ} \mathrm{C}$ for 10 minutes. The resultant reaction mixture was stored at $4^{\circ} \mathrm{C}$. The PCR products were loaded and visualized in 1\% Agarose gel electrophoresis stained with Ethidium Bromide in a X0.5 Tris Acetate EDTA buffer at $100 \mathrm{~V}$ for 30 minutes to determine the DNA size through visualization under UV light.

\subsection{Sanger Sequencing of the Coat Protein (CP) Gene}

Sanger sequencing of the coat protein (CP) gene PCR amplicons was done with the Taq terminator sequencing Kit (Applied Biosystems) and followed by analysis of $\mathrm{CP}$ sequences on an Applied Biosystem 373A sequencer [14, 16]. Two readings per base (3' to 5' and 5' to 3' directions) led to sequence accuracy of $99.9 \%$. Assembling of sequences was done by Seqman (DNASTAR) and sequence analysis was done by MEGA X software. The sequences of the CP gene with $1000 \mathrm{bp}$ (Figure 2) isolates were compared with reference strains in the GenBank and they were useful in determination of intra-strain diversity.

\section{Results}

\subsection{Serological Detection of RYMV}

Seven samples $1,3,5,7,8,9$ and 10 representing A1, A3, A5, B2, B3, B4 and B5 tested positive for RYMV (Figure 1). Sample 4 (A4) was a healthy leaf sample from western Kenya while sample 6 (B1) was negative control from IRD and sample 9 (B4) was positive control. These results are epidemiologically explained in the viral titre reads (Table 1).

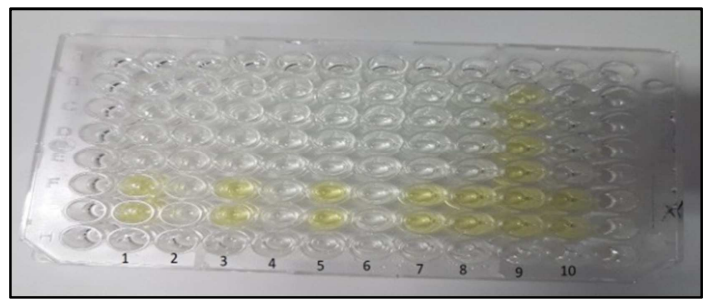

Figure 1. DAS-ELISA plate of results for RYMV.

Table 1. DAS-ELISA reads OD at $405 \mathrm{~nm}$.

\begin{tabular}{|c|c|c|c|c|c|c|c|c|c|}
\hline 1 & 2 & 3 & 4 & 5 & 6 & 7 & 8 & 9 & 10 \\
\hline 0.00 & 0.00 & 0.00 & 0.00 & 0.00 & 0.00 & 0.00 & 0.00 & 1.05 & 0.00 \\
\hline 11 & 12 & 13 & 14 & TS & 15 & 17 & 19 & A1 & $\mathrm{A} 2$ \\
\hline 0.00 & 0.00 & 0.00 & 0.00 & 0.00 & 0.00 & 0.00 & 0.00 & 1.60 & 0.00 \\
\hline A3 & A4 & A5 & $\mathrm{AH}$ & B1 & B2 & B3 & B4 & TV & B5 \\
\hline 1.47 & 0.00 & 1.42 & 0.00 & 1.55 & 0.00 & 1.35 & 1.39 & 1.43 & 1.50 \\
\hline
\end{tabular}

\subsection{Two-step RT-PCR Diagnostics}

The agarose gel electrophoresis view of RT-PCR products for RYMV isolates.



Figure 2. Gel electrophoresis of RYMV RT-PCR products

Lane M- 1kb Ladder, Isolates in lanes 1-4 Ahero, 5-Negative control, 6Positive control (RT), 7-Positive control (PCR).

\subsection{Phylogenetic Analysis of RYMV}

Sequences for isolates Ke_A1, KeB3 and KeB4 clustered together with already described Kenyan isolates. Four distinct clusters were formed each one from individual countries of
Uganda, Kenya and Tanzania except those from Congo, Rwanda and Burundi which clustered together (Figure 3).

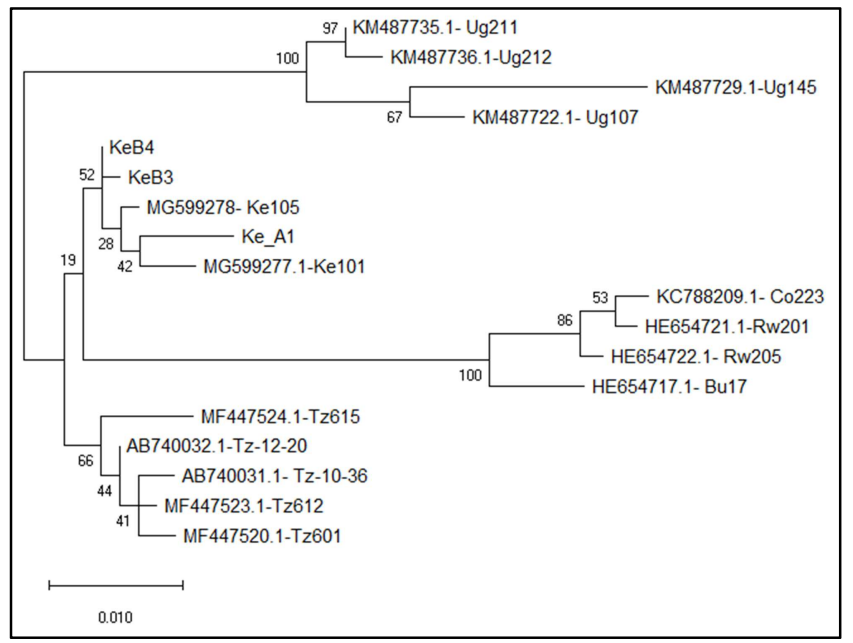

Figure 3. Phylogenetic analysis of the isolates and sequences selected from the GenBank.

The evolutionary history was inferred using the Maximum Likelihood method based on the Tamura-Nei model [17]. The bootstrap values are shown next to the various branches. The phylogenetic tree is drawn to scale, with branch lengths per clade measured in the number of substitutions per site. The 
analysis involved 18 nucleotide sequences. Evolutionary analyses was conducted in MEGA X [18]. The sequences for western Kenya RYMV isolates of Ke_A1, KeB3 and KeB4 were deposited in the GenBank with accession numbers LC547477, LC547478 and LC547479 respectively.

\section{Discussion}

The RYMV symptoms observed in the rice field included yellow leaves, yellow stripes \& brown/orange discolouration of older leaves, leaf narrowing, leaf mottling, stunting, leaf necrosis, reduced tillering, crinkling, malformation, incomplete emergence of the panicles and plant death. [19,2] All the symptomatic samples tested positive for RYMV by DAS-ELISA. These findings indicate that isolates originating from the same field are similar serologically but with different optical density (OD) values suggesting diversity of the virus strains (Table 1). This disease encounter phenomenon can be unravelled through full genome characterization at both the $\mathrm{CP}$ gene and nucleic acid levels. The two-step RT-PCR molecular diagnostic bioassay confirmed presence of RYMV in the seven samples. The PCR amplified fragments produced the expected band size of $850 \mathrm{bp}$ on the gel. The CP gene sequences of the seven isolates had the same base pair length of $720 \mathrm{bp}$ and were found to be of RYMV strains S4, S5 and S6. This confirms earlier findings by [14] that isolates of RYMV strain S4 have been reported to occur solely in the East African region. Since RYMV was first reported at Ahero in Kisumu County in 1966 [19], the virus seems to be gradually evolving into mutant strains resulting into novel strains that causes phylogenetic diversity, which is in agreement with findings by $[20,21]$.

Phylogenetic analysis of the CP gene sequences revealed that the isolates from Uganda $(\mathrm{Ug})$, Kenya $(\mathrm{Ke})$ and Tanzania (Tz) clustered together by country of origin implying that there was a single introduction of the RYMV CP gene in the three East African (EA) regions once, before further local viral diversity occurred in each specific country. Ke_A1, $\mathrm{KeB} 3$ and KeB4 are novel sequences of RYMV isolates from western Kenya. The two isolates of KeB4 and KeB3 shared $99 \%$ sequence identity with $\mathrm{Ke} 105$ and Ke101, but isolate Ke_A1 shared 98\% identity with Ke101 and 99\% with $\mathrm{Ke} 105$. The $\mathrm{Ke} \mathrm{A} 1$ isolate is closely related to $\mathrm{Ke} 101$ in the same sub-cluster closer to Ke105 with a more stable clustering relationship. $\mathrm{KeB} 3$ and $\mathrm{KeB} 4$ isolates clustered together because they might not be similar, but are uniquely different from the other Kenyan sequences depicting new phenomenon in RYMV evolutionary genomics. The isolates from Congo (Co), Rwanda $(\mathrm{Rw})$ and Burundi $(\mathrm{Bu})$ clustered together but they present a likely different bottleneck scenario of having very few sequences, which indicate a possibility of Burundi not to might have had the RYMV CP gene introduced from any of the three EA countries ( $\mathrm{Ug}, \mathrm{Ke}$ and $\mathrm{Tz}$ ).

\section{Conclusion}

The high incidence and severity of RYMV in western Kenya is attributed to evolutionary genetic diversity of major RYMV strains among the rice isolates contributing to RYMD. This study has unravelled vital genetic information for crop protection technologies and germplasm screening to curb mixed infections among susceptible IR rice varieties for RYMV resistance/tolerance breeding as the only practical solution. Genomic diversity studies of RYMV strains to be enhanced and identify the evolutionary relationship that exists in western Kenya. This will provide sufficient knowledge for utilization by plant breeders to reduce their frequency and occurrence in rice fields.

\section{Conflict of Interest}

All the authors declare no conflict of interest.

\section{Acknowledgements}

The financial support for this laboratory learning study visit was provided by the Biotechnology and Biological Sciences Research Council (BBSRC), Funding Body Reference-BB/R005397/1 under the Project "CONNECTED - Community Network for African Vector-Borne Plant Viruses" by the Global Challenges Research Fund (GCRF) Research Grant, facilitated by the department of Life Sciences, University of Bristol, United Kingdom (UK).

Sincere gratitude to the department of Unit Interactions Plantes Microorganismes Environnement (UMR IPME), at the Institut de Recherche pour le Développement (IRD), Montpellier, France, for purchasing the serological and molecular diagnostic reagents and paying for the Sanger sequencing costs.

The funding bodies together with collaborators had no role in the study design, data collection and interpretation or the decision to submit the work for publication.

\section{References}

[1] Lidejere, M. I. (2012). Variations in the Coat Protein Gene of Rice yellow mottle virus isolates from Western Kenya. Msc. Thesis. Masinde Muliro University of Science and Technology, Kenya.

[2] Adego, A. K., Wéré, H. K., Muoma, J., Mukoye, B., Hébrard, E., Pinel-Galzi, A., Poulicard, N. and Fargette, D. (2017). Current status of rice yellow mottle virus in western Kenya. Research Journali's Journal of Agriculture. 4 (9): 1-12.

[3] Kouassi, N. K., N'Guessan, P., Albar, L., Fauquet, C. \& Brugidou, C. (2005). Distribution and characterization of Rice yellow mottle virus: a threat to African farmers. Plant Disease. 89: 124-132.

[4] Rakotomalala, M., Vrancken, B., Pinel-Galzi, A., Ramavovololona, P., He'brard, E., Randrianangaly, J. S., Dellicour, S., Lemey, P. and Fargette, D. (2019). Comparing patterns and scales of plant virus phylogeography: Rice yellow mottle virus in Madagascar and in continental Africa. Virus Evolution. 5 (2): vez023. 
[5] Ochola, D. \& Tusiime, G. (2011). Survey on Incidences and Severity of Rice Yellow Mottle Virus Disease in Eastern Uganda. International Journal of Plant Pathology. 2: 15-25.

[6] Kanyeka, Z. L., Sangu, E., Fargette, D., Pinel-Galzi, A. \& Hérbrard, E. (2007). Distribution and diversity of local strains of Rice yellow mottle virus in Tanzania. African Crop Science Journal. 15: 201-209.

[7] Lidejere, M. I. et al., (2012). Variations in the Coat Protein Gene of Rice yellow mottle virus isolates from Western Kenya Msc. Thesis. Masinde Muliro University of Science and Technology, Kenya.

[8] Ndikumana, I., Pinel-Galzi, A., Fargette, D. \& Hebrard, E. (2017). Complete genome sequence of a new strain of Rice yellow mottle virus from Malawi, characterized by a recombinant VPg protein. Genome Announcement. 5: e0119817.

[9] Fargette, D., Pinel, A., Halimi, H., Brugidou, C., Fauquet, C. and Van Regenmortel, M. (2002a). Comparison of molecular and immunological typing of the isolates of Rice yellow mottle virus. Archives of Virology. 147: 583-596.

[10] Traoré, O., Sorho, F., Pinel, A., Abubakar, Z., Banwo, O., Maley, J., Hébrard, E., Winter, S., Séré, Y., Konaté, G. \& Fargette, D. (2005). Processes of diversification and dispersion of Rice yellow mottle virus inferred from largescale and high-resolution phylogeographical studies. Molecular Ecology. 14: 2097-2110.

[11] King, A. et al. (2018). Changes to Taxonomy and the International Code of Virus Classification and Nomenclature Ratified by the International Committee on Taxonomy of Viruses. Archives of Virology. 163: 2601-31.

[12] Ling, R. et al. (2013). An Essential Fifth Codon ORF in the Sobemoviruses. Virology. 446: 397-408.

[13] Adego, A. K., Poulicard, N., Pinel-Galzi, A., Mukoye, B., Fargette, D., Wéré, H. K. and Hébrard, E. (2018). Full-length genome sequences of recombinant and non-recombinant sympatric strains of Rice yellow mottle virus from western Kenya. Genome Announcements. 6 (8): e01508-17.
[14] Pinel, A., N'Guessan, P., Bousalem, M. \& Fargette, D. (2000). Molecular variability geographically distinct isolates of rice yellow mottle virus in Africa. Archives of Virology. 145: 16211638 .

[15] Ochola, D., Issaka, S., Rakotomalala, M., Pinel-Galzi, A., Ndikumana, I., Hubert, J., Hébrard, E., Séré, Y., Tusiime, G. and Fargette, D. (2015). Emergence of rice yellow mottle virus in eastern Uganda: recent and singular interplay between strains in East Africa and in Madagascar. Virus Research. 195: 64-72.

[16] Fargette, D., Pinel, A., Abubakar, Z., Traoré, O., Brugidou, C., Fatogoma, S., Hébrard, E., Choisy, M., Séré, Y., Fauquet, C. \& Konaté, G. (2004). Inferring the evolutionary history of rice yellow mottle virus from genomic, phylogenetic, and phylogeographic studies. Journalof Virology. 78: 3252-3261.

[17] Tamura, K. \& Nei, M. (1993). Estimation of the number of nucleotide substitutions in the control region of mitochondrial DNA in humans and chimpanzees. Molecular Biology and Evolution. 10: 512-526.

[18] Kumar, S., Stecher, G., Li, M., Knyaz, C. \& Tamura, K. (2018). MEGA X: Molecular Evolutionary Genetics Analysis across computing platforms. Molecular Biology and Evolution. 35: $1547-1549$.

[19] Bakker W (1974). Characterisation and ecological aspects of Rice yellow mottle virus in Kenya. Ph. D. Thesis. University of Wageningen, The Netherlands.

[20] Hébrard, E., Pinel-Galzi, A. \& Fargette, D. (2008). Virulence domain of the RYMV genome-linked viral protein VPg towards rice rymv1-2-mediated resistance. Archives of Virology. 153: 1161-11648.

[21] Poulicard, N., Pinel-Galzi, A., Hébrard, E. \& Fargette, D. (2010). Why Rice yellow mottle virus, a rapidly evolving RNA plant virus, is not efficient at breaking rymv1-2 resistance. Molecular Plant Pathology. 11: 145-154. 